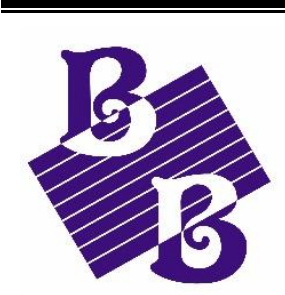

BioBacta

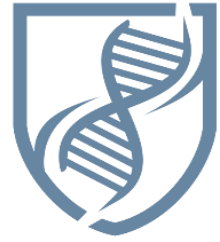

Journal of Bioscience and Applied Research

www.jbaar.org

\title{
Effect of boswellic acid in Alzheimer's disease in experimental rat
}

\author{
Mai M. El-Keiy ${ }^{1}$, Menna Allah M. Youssef ${ }^{2}$, Azza A. Bakry² and Tarek M. Mohamed ${ }^{1}$ \\ 1 Biochemistry Department, Faculty of Science, Tanta University, Egypt \\ 2 Food Technology Research Institute, Agricultural Research Centre, Giza, Egypt. \\ *Corresponding to Mai M. El-Keiy, lecturer of Biochemistry, mai1980 ahmed@hotmail.com
}

DOI: $10.21608 / J B A A R .2019 .147093$

\begin{abstract}
Alzheimer's disease (AD) is the most common age-related dementia characterized by cognitive decline and devastating neurodegeneration. Present work aimed to evaluate the role of bioactive component boswellic acid in improving cholinergic deficiency in an experimental rat model. In this study, rats were divided into five groups as group 1 (control group), group 2 (boswellic acid group), group 3 (AD group), group 4 (boswellic acid -pretreated group), and group 5 (boswellic acid-treated group). At the end of the experiment different neurochemicals, a biochemical analysis was assessed. In the AD group (G3) acetylcholine was decreased with acetylcholinesterase elevation as compared to the control groups (G1 and G2). Improvement of acetylcholinesterase activity and acetylcholine level was observed after pre and treated (G4 and G5) by boswellic acid. There was a significant decrease in the dopamine in the hippocampus of the AD group (G3)as compared to the control groups (G1 and G2).In contrast, pretreated and treated groups by boswellic acid (G4 and G5, respectively) led to an elevation of dopamine concentration, with the best improvement in a pre-treated group $(\mathrm{G} 4)$ than the treated group (G5). In conclusion; bowsellic acid improved the cholinergic deficiency in Alzheimer's disease.
\end{abstract}

Keywords: bowsellic acid, Alzheimer's disease, cholinergic deficiency, resistance in Alzheimer's disease brain.

\section{Introduction}

Alzheimer's disease (AD) is the most common cause of disability in individuals aged $>65$ years worldwide with declining in memory, attention, and language, associated with a cholinergic deficiency in the cerebral cortex, and the increase in concentration of acetylcholine with acetyl cholinesterase inhibition (Hampel, Mesulam et al. 2018). The hallmarks of the disease are extracellular accumulation of beta-amyloid amide (A $\beta)$ and intracellular accumulation of tau (Drummond, Nayak et al. 2018)Acetylcholine (ACh) contains a crucial role within the peripheral and central nervous systems. The enzyme acetyl choline transferase (ChAT) is responsible for synthesizing ACh from acetyl-CoA and choline within the cytoplasm and the vesicular acetylcholine transporter (VAChT) 
uptakes the neurotransmitter into synaptic vesicles. Following depolarization, ACh undergoes exocytosis reaching the synaptic cleft, where it will bind its receptors, together with muscarinic and nicotinic receptors. ACh present at the synaptic cleft is promptly hydrolyzed by the enzyme acetylcholine esterase (AChE), forming acetate and choline, That is recycled into the presynaptic nerve terminal by the high-affinity choline transporter (CHT1) (H Ferreira-Vieira, M Guimaraes et al., 2016).Today, medicinal herbs have been widely used because of anti-inflammation properties, antioxidants and less harmful than chemical compounds. Boswellia serrata (frankincense) It mostly usage in Ayurvedic medicine, Traditional Chinese Medicine, the Middle East and other tropical regions (Samani et al., 2011). Boswellia serrata extract exhibited strong reducing power, antioxidant activity and anti-inflammatory. In recent years analysis has been progressed within the exploitation of medicinal plants, within the treatment of varied stress related disorders caused by metabolism of oxygen leads to generation of free radicals concerned in the various diseases like diabetes mellitus, cancer, coronary artery disease, arthritis, and neurodegenerative diseases (Afsar, Reddy et al., 2012) Boswellic acids (BAs) are common chemical characteristic of all species of frankincense (Farah et al., 2017). Six major boswellic acids have biological activities that include immunomodulation, anti-inflammatory drug, anticancer and antiviral properties. (Mehta, Satija et al., 2014).

The present study aims to evaluate the role of boswellic acid from the medicinal plant $B$. serratta in the improvement of cholinergic deficiency insults characteristic of Alzheimer's disease. To achieve this purpose the following biochemical parameters were carried out.

\section{Materials and Methods}

\section{Chemicals}

Boswellic acid was purchased from the Shanghai Research Institute of the Chemical Industry Testing
Center (90\%). $\quad \beta$-amyloid, D-galactose, and Carboxymethylcellulose (CMC) were purchased from Sigma (USA).

\section{Experimental design}

This experiment was carried out following the Egyptian ethical committee of Tanta University, Faculty of Science for studies on experimental animals. 50 adult male albino rats were obtained from the Faculty of Pharmacy, Alexandria University aged about 4months and weighing approximately $220-250 \mathrm{~g}$. Animals have housed in wire mesh cages and allowed to adapt to the laboratory conditions for one week. Rats have wolfed an advertisement customary diet spontaneously with free access to water. The animals were exposed to 12:12-h light-dark cycles at a temperature of approximately $25^{\circ} \mathrm{C}$. All animals were weighed before and after the experiment. All rats were randomly divided into five groups with ten rats in every group and classified as group one (control group) rats received distilled $\mathrm{H} 2 \mathrm{O}$ orally, group 2 (boswellic acid group): rats were intraperitoneally injected with boswellic acid at a concentration of $250 \mathrm{mg} / \mathrm{kg}$ body weight (bw) (suspended in CMC0.5g per100ml water $(0.5 \%)$ )daily for 3 weeks (Asheeshet al., 2014). Group 3 (AD group): rats were intra cerebroventriculary injected with a single dose of $0.2 \mu \mathrm{g} / \mu \mathrm{L}$ amyloid ${ }_{1-24}$ in both lateral ventricles at day 1 of the experiment and intraperitoneally injected with D-galactose at a concentration of $250 \mathrm{mg} / \mathrm{kg}$ bw daily for 8 weeks (Faucheret al. 2016; Kong, Li et al. 2018). Group 4 (boswellic acid -pre-treated group): rats were intraperitoneally injected with $250 \mathrm{mg} / \mathrm{kg}$ bwboswellic acid daily for 3 weeks and were intracerebroventriculary injected with a single dose of 0.2 $\mu \mathrm{g} / \mu \mathrm{L}$ B amyloid ${ }_{1-42}$ then rats were intraperitoneally injected with $250 \mathrm{mg} / \mathrm{kg}$ bw D-galactose daily for 8weeks. Group 5 (boswellic acid-treated group): rats were intra-cerebroventricular injected with a single dose of $0.2 \mu \mathrm{g} / \mu \mathrm{LB}$ amyloid ${ }_{1-42}$ and intraperitoneal injected with $250 \mathrm{mg} / \mathrm{kg}$ bw D-galactose daily for 8 weeks then $250 \mathrm{mg} / \mathrm{kg}$ bwboswellic acid daily for 3weeks. 


\section{Estimation of biochemical parameters}

Blood glucose level was estimated according to the enzymatic method by Trinder (1969). Serum aspartate aminotransferase activity was determined according to the kinetic methodology designed by Schumann et al., (2002). Serum alanine aminotransferase activity was determined according to the kinetic method described by Schumann et al., (2002), serum Creatinine determination was according to a kinetic method of Chary and Sharma(2004). Urea determination was according to the enzymatic method of Malhotra (2003). Rat Dopamine (DA) was measured using Rat Dopamine (DA) ELISA kit following the manufacturer protocol (My BioSource Cat.No. MBS7214676). Acetylcholine was measured using Rat acetylcholine $(\mathrm{ACH})$ Elisa kit following the manufacturer protocol (My BioSource Cat. No MBS282680). Acetylcholinesterase was measured using Rat Acetylcholinesterase (Ache) Elisa kit following the manufacturer protocol (My BioSource Cat. No. IT6861).

\section{Statistical analysis}

All the data were expressed as means that \pm S.E. The statistical significance was evaluated by one-way analysis of variance (ANOVA) using SPSS, 18.0 software, 2011 and therefore the individual comparisons were obtained by Duncan's multiple range test (DMRT). Values were considered statistically significant when $\mathrm{p}<0.05$.

\section{Results}

There was a significant increase in blood levels of glucose in the AD group (G3) as compared to control groups, (G1 and G2) (Table1 ). These increased levels were significantly reduced following either pretreatment (G4) and treatment group (G5) by boswellic acid. Our results exhibited a significant increase in activity of alanine aminotransferase and aspartate aminotransferase in the $\mathrm{AD}$ group (G3) as compared to control groups (G1, G2) (Table 1). These increased levels were significantly reduced following either pretreatment (G4) or treatment (G5) by boswellic acid groups Moreover, a significant increase in levels of Creatinine and Urea in the AD group (G3) as compared to control groups $(\mathrm{G} 1, \mathrm{G} 2)$ (Table 1). These increased levels were significantly reduced following either pretreatment (G4) or treatment (G5) by boswellic acid groups.

The levels of dopamine, acetylcholine were significantly decreased in the AD group (G3) as compared to the control groups (G1 and G2) (Table 2). These decreased levels were elevated after pre- (G4) and (G5) treatment by boswellic acid groups. On the other hand, acetylcholinesterase activity was significantly increased in the AD group (G3) as compared to the control groups (G1 and G2). The activity was decreased on pretreated- (G4) and treated (G5) by boswellic acid groups (Table 2). 
Table 1: Effect of boswellic acid treatment on blood glucose level, serum AST and ALT activity, creatinine and urea in chemically induced $\mathrm{AD}$ model in rats.

\begin{tabular}{|l|c|c|c|c|c|}
\hline $\begin{array}{l}\text { Animal } \\
\text { groups }\end{array}$ & $\begin{array}{c}\text { glucose level } \\
(\mathbf{m g} / \mathbf{1 0 0 m l}) \\
\text { Mean } \pm \\
\text { SEM }\end{array}$ & $\begin{array}{c}\text { AST(U/I) } \\
\text { Mean } \pm \text { SEM }\end{array}$ & $\begin{array}{c}\text { ALT(U/I) } \\
\text { Mean } \pm \text { SEM }\end{array}$ & $\begin{array}{c}\text { Urea } \\
\text { level(mg/d) } \\
\text { Mean } \pm \text { SEM }\end{array}$ & $\begin{array}{c}\text { Creatinine level(mg/dl) } \\
\text { Mean } \pm \text { SEM }\end{array}$ \\
\hline $\begin{array}{l}\text { Normal control } \\
(\text { G1 })\end{array}$ & $114.34 \pm 4.04^{\mathrm{c}}$ & $47.53 \pm 2.32^{\mathrm{d}}$ & $39.22 \pm 1.47^{\mathrm{d}}$ & $25.40 \pm 1.01^{\mathrm{d}}$ & $0.95 \pm 0.03^{\mathrm{d}}$ \\
\hline $\begin{array}{l}\text { Boswellic acid } \\
(\mathrm{G} 2)\end{array}$ & $117.60 \pm 5.14^{\mathrm{c}}$ & $48.60 \pm 2.01^{\mathrm{d}}$ & $43.62 \pm 2.55^{\mathrm{d}}$ & $26.67 \pm 1.09^{\mathrm{d}}$ & $1.01 \pm 0.06^{\mathrm{d}}$ \\
\hline $\begin{array}{l}\text { B amyloid and } \\
\text { D-galactose } \\
(\text { G3 })\end{array}$ & $218.58 \pm 7.08^{\mathrm{a}}$ & $102.36 \pm 5.45^{\mathrm{a}}$ & $83.09 \pm 4.11^{\mathrm{a}}$ & $44.13 \pm 1.11^{\mathrm{a}}$ & $2.43 \pm 0.09^{\mathrm{a}}$ \\
\hline $\begin{array}{l}\text { Boswellic acid } \\
\text { pre-treated } \\
(G 4)\end{array}$ & $143.72 \pm 4.45^{\mathrm{b}}$ & $63.03 \pm 2.86^{\mathrm{c}}$ & $54.43 \pm 2.41^{\mathrm{b}}$ & $30.12 \pm 0.90^{\mathrm{c}}$ & $1.48 \pm 0.11^{\mathrm{c}}$ \\
\hline $\begin{array}{l}\text { Boswellic acid } \\
\text { treated (G5) }\end{array}$ & $148.90 \pm 5.02^{\mathrm{b}}$ & $74.65 \pm 3.27^{\mathrm{b}}$ & $67.25 \pm 2.27^{\mathrm{c}}$ & $34.38 \pm 0.83^{\mathrm{b}}$ & $1.80 \pm 0.07^{\mathrm{b}}$ \\
\hline
\end{tabular}

Data are presented as mean \pm SEM (standard error of the mean), $n=7$ per group. Mean values with different superscript letters in the same column are significantly different at $(\mathrm{P} \leq 0.05)$. 
Table 2: Effect of boswellic acid treatment on hippocampus level of dopamine in chemically induced AD model in rats.

\begin{tabular}{|l|r|r|r|}
\hline \multirow{2}{*}{ Animal groups } & $\begin{array}{c}\text { Dopamine } \\
\text { (ng/g tissue) }\end{array}$ & $\begin{array}{c}\text { Acetylcholine } \\
\text { (ng/g tissue) }\end{array}$ & $\begin{array}{c}\text { Acetylcholine } \\
\text { esterase } \\
\text { (mol/min/g tissue) }\end{array}$ \\
\cline { 2 - 4 } & Mean \pm SEM & Mean \pm SEM & Mean \pm SEM \\
\hline Normal control group(G1) & $647.42 \pm 22.11^{\mathrm{a}}$ & $110.43 \pm 4.11^{\mathrm{a}}$ & $0.165 \pm 0.006^{\mathrm{c}}$ \\
\hline Boswellic acid group(G2) & $669.12 \pm 21.75^{\mathrm{a}}$ & $117.09 \pm 3.5^{\mathrm{a}}$ & $0.161 \pm 0.005^{\mathrm{c}}$ \\
\hline AD group (G3) & $407 \pm 21.8^{\mathrm{c}}$ & $60.44 \pm 2.12^{\mathrm{d}}$ & $0.223 \pm 0.007^{\mathrm{a}}$ \\
\hline $\begin{array}{l}\text { Boswellic acid pre-treated } \\
\text { group(G4) }\end{array}$ & $516.35 \pm 22.69^{\mathrm{b}}$ & $101.22 \pm 2.00^{\mathrm{b}}$ & $0.189 \pm 0.006^{\mathrm{b}}$ \\
\hline $\begin{array}{l}\text { Boswellic acid treated } \\
\text { group(G5) }\end{array}$ & $495.21 \pm 20.31^{\mathrm{b}}$ & $90.27 \pm 2.1^{\mathrm{c}}$ & $0.200 \pm 0.007^{\mathrm{b}}$ \\
\hline
\end{tabular}

Data are presented as mean \pm SEM (standard error of the mean), $n=3$ per group. Mean values with different superscript letters in the same column are significantly different at $(\mathrm{P} \leq 0.05)$.

\section{Discussion}

The result of the present study showed significant elevation in blood glucose level In the $\mathrm{AD}$ group compared to the control group. These results conform with (Burns, Chen, et al. 2013) who reported that higher blood glucose levels in cognitively normal, may be associated with $\mathrm{AD}$ pathophysiology. Insulin resistance in the $\mathrm{AD}$ brain is a response to( ADDLs)amyloid beta-derived diffusible ligands, which disrupt endocrine communication and should cause a brain-specific type of diabetes (Zhao, De Felice, et al., 2008). The brain of patients with Alzheimer's disease (AD) showed evidence of reduced expression of endocrine and neuronic insulin receptors, as compared with those of age-matched controls. This event step by step and certainly leads to a breakdown of the whole insulin-signaling pathway, Which manifests insulin resistance (Leszek, Trypka, et al., 2017). Our results exhibited a significant increase in activity of alanine aminotransferase and aspartate aminotransferase in the $\mathrm{AD}$ group (G3) as compared to the control group. overload of d-galactose (d-gal) will increase the production of ROS, leading to oxidative stress which will attack essential cell constituents, induce lipid peroxidation, harm the membranes of cells and organelles in the liver, cause the swelling and necrosis of hepatocytes therefore as compared to the control group, the serum ALT and AST levels of the mice within the AD group were significantly increased (Gao, Yu et al. 2018). The result of the present study showed a significant increase in levels of creatinine and urea in the AD group (G3) as compared to the control groups. These results confirm by (Erbayraktar, Evlice, et al., 2017) who indicate that significantly evaluated serum creatinine levels in different age groups of patients with $\mathrm{AD}$. Administration of D-gal for 8 weeks(100-500 mg/kg body weight)induced oxidative stress and nephropathy in mice and significantly increased creatinine and urea levels in $\mathrm{AD}$ groups (Feng, Yu et al, 2016). The result of the present 
study showed that significant increase in acetylcholinesterase (AChE) activity and a significant decrease in acetylcholine neurotransmitter in the hippocampus of the $\mathrm{AD}$ rat group compared with a control group. Other results supported these results, Patients in whom Alzheimer's disease was histologically confirmed, acetylcholine significantly reduced (at least 40\%) below mean control values (Sims, Bowen, et al., 1983). deficits in acetylcholine release in biopsy tissue from living patients with Alzheimer's disease and increased in acetylcholinesterase (Davies 1999). The second important neurotransmitter dopamine. In our present study significant decrease in dopamine in the hippocampus of the $\mathrm{AD}$ group compared with the Control group .dopaminergic system may well be involved in the occurrence of cognitive decline, often being predictive of rapidly progressive forms of $\mathrm{AD}$ (Martorana and Koch. 2014). Similar result (Nobili, Latagliata et al., 2017) showed that a significant loss of dopaminergic DA ergic neurons in the hippocampus of $\mathrm{Tg} 2576$ mice mouse model of $\mathrm{AD}$ compared to control, which might largely contribute to the deficits of hippocampus-dependent memory and synaptic plasticity. Extracellular concentrations of dopamine were significantly decreased compared with young rats and dopamine was partially improved by Yokukansan (YKS) treatment (Mizoguchi, Tanaka et al. 2010).

\section{References}

Afsar, V., et al. (2012). "In vitro antioxidant activity and anti-inflammatory activity of methanolic leaf extract of Boswellia serrata." International Journal of Life Sciences Biotechnology and Pharma Research1(4): 15-23.

Asheesh, NB., et al. (2014). "Effect of Boswellic Acids in Gentamicin-Induced Nephpotoxicity In Rats" Indian Pharmacological Society-North Zone Conference-In February 15-16, 2014.
Burns, C. M., et al. (2013). "Higher serum glucose levels are associated with cerebral hypometabolism in Alzheimer regions." Neurology80(17): 1557-1564.

Davies, P. (1999). "Challenging the cholinergic hypothesis in Alzheimer disease." Jama281(15): 14331434.

Drummond, E., et al. (2018). Isolation of amyloid plaques and neurofibrillary tangles from archived alzheimer's disease tissue using laser-capture microdissection for downstream proteomics. Laser Capture Microdissection, Springer: 319-334.

Erbayraktar, Z., et al. (2017). "Evaluation of Renal Function in Alzheimer's Disease and Geriatric Patients: Results from a Turkish Two-Center Study." Journal of medical biochemistry36(1): 54-61.

Faucher, P., Mons, N., Micheau, J., Louis, C. and Beracochea, D. J. (2016): Hippocampal injections of oligomeric amyloid $\beta$-peptide (1-42) induce selective working memory deficits and long-lasting alterations of ERK signaling pathway. Frontiers in Aging Neuroscience, 7, 245.

Farah, I., Shah, K. A. and Asif, H. (2017): Phytochemistry and potential therapeutic actions of Boswellic acids: A mini-review. Asian Pacific Journal of Tropical Biomedicine, 7(6), 513-523.

Feng, Y., et al. (2016). "Chlorogenic acid protects Dgalactose-induced liver and kidney injury via antioxidation and anti-inflammation effects in mice." Pharmaceutical biology54(6): 1027-1034.

Gao, J., et al. (2018). "Protective effect of Anwulignan against D-galactose-induced hepatic injury through activating p38 MAPK-nrf2-hO-1 pathway in mice." Clinical interventions in aging13: 1859.

H Ferreira-Vieira, T., et al. (2016). "Alzheimer's disease: targeting the cholinergic system." $\underline{\text { Current }}$ neuropharmacology14(1): 101-115. 
Hampel, H., et al. (2018). "The cholinergic system in the pathophysiology and treatment of Alzheimer's disease." Brain141(7): 1917-1933.

Kong, S.-Z., Li, J.-C., Li, S.-D., Liao, M.-N., Li, C.-P., Zheng, P.-J., Guo, M.-H., Tan, W.-X., Zheng, Z.-H. and Hu, Z. (2018): Anti-aging effect of chitosan oligosaccharide on d-galactoseinduced subacute aging in mice. Marine drugs, 16(6), 181.

Leszek, J., et al. (2017). "Type 3 diabetes mellitus: a novel implication of Alzheimers disease." Current topics in medicinal chemistry 17(12): 1331-1335.

Nobili, A., Latagliata, E. C., Viscomi, M. T., Cavallucci, V., Cutuli, D., Giacovazzo, G., Krashia, P., Rizzo, F. R., Marino, R. and Federici, M. (2017): Dopamine neuronal loss contributes to memory and reward dysfunction in a model of Alzheimer's disease. Nature communications, 8, 14727.

Samani, M. K., Mahmoodian, H., Moghadamnia, A., Mir, A. P. B. and Chitsazan, M. (2011): The effect of Frankincense in the treatment of moderate plaque-induced gingivitis: a double blinded randomized clinical trial. Daru: Journal of Faculty of Pharmacy, Tehran University of Medical Sciences, 19(4), 288.

Sims, N., et al. (1983). "Presynaptic cholinergic dysfunction in patients with dementia." Journal of neurochemistry40(2): 503-509.

Zhao, W.-Q., et al. (2008). "Amyloid beta oligomers induce impairment of neuronal insulin receptors." The FASEB Journal22(1): 246-260.

Martorana, A. and G. Koch (2014). "Is dopamine involved in Alzheimer's disease?" Frontiers in aging neuroscience 6: 252.
Chary, T. M. and Sharma, H. (2004): Practical Biochemistry for Medical and Dental Students. Jaypee Brothers Medical Publishers (p) LTD, New Delhi.

Mizoguchi, K., et al. (2010). "Anxiolytic effect of a herbal medicine, yokukansan, in aged rats: involvement of serotonergic and dopaminergic transmissions in the prefrontal cortex." Journal of ethnopharmacology127(1): 70-76.

Malhotra, V. K. (2003): Practical Biochemistry for Students. Fourth Edition, Jaypee Brothers Medical Publishers (p) LTD, New Delhi.

Trinder, P. (1969): Glucose enzymatic colorimetric method. J. Ann. Clin. Biochem., 6: 24-33. 